-Original Article-

\title{
Forensic Discrimination of Steel Wires by Quantitative Elemental Analysis with ICP-MS
}

\author{
Hiroyuki Ohsaki, ${ }^{{ }_{1}}$ Katsunori Murakami, ${ }^{* 1}$ Masaaki Kasamatsu, ${ }^{* 2}$ \\ Yasuhiro Suzuki*3 and Shinichi Suzuki*3 \\ Criminal Investigation Laboratory, Hiroshima Prefectural Police H.Q. ${ }^{* 1}$ \\ 2-26-3, Konan, Nakaku, Hiroshimashi, 730-0825, Japan \\ Criminal Investigation Laboratory, Saitamama Prefectural Police H.Q. ${ }^{* 2}$ \\ 3-10-1, Kizaki, Urawaku, Saitamashi, 330-0042 \\ National Research Institute of Police Science ${ }^{* 3}$ \\ 6-3-1, Kashiwanoha, Kashiwa, Chiba 277-0882
}

(Received 24 March 2009; accepted 13 May 2009)

The application of inductively coupled plasma mass spectrometry (ICP-MS) in the determination of the concentrations of trace elements in steel wires was investigated for the forensic discrimination of wires with different origins; the discrimination is carried out by comparing elemental compositions. Approximately $5 \mathrm{mg}$ of a chip taken from the wire was accurately weighed and dissolved in a mixture of $100 \mu \mathrm{l} \mathrm{HCl}$ and $100 \mu \mathrm{HNO}_{3}$ by heating at $80^{\circ} \mathrm{C}$ for $30 \mathrm{~min}$. Following the addition of $100 \mu \mathrm{l}$ of $5 \mu \mathrm{g} / \mathrm{ml} \mathrm{Y}$ as an internal standard and $200 \mu \mathrm{l}$ of $7 \mathrm{M} \mathrm{HCl}$, the matrix iron in the solution was removed by extraction with $200 \mu \mathrm{l} \mathrm{MIBK}$. This extraction was repeated twice, and $300 \mu \mathrm{l}$ of the aqueous phase was heated at $150^{\circ} \mathrm{C}$ for $1 \mathrm{~h}$ after the addition of $250 \mu \mathrm{H} \mathrm{H}_{2} \mathrm{SO}_{4}$. This solution was diluted to $25 \mathrm{ml}$ by $1 \%$ $\mathrm{HNO}_{3}$, and then the solution was used to determine the concentrations of $\mathrm{Cr}, \mathrm{Mn}$, $\mathrm{Ni}$ and $\mathrm{Cu}$ by ICP-MS. The measured values of these elements in NIST 16f (Steel Basic Open-Hearth) showed satisfactory good agreement with the certified values with RSDs from 1.0 to $2.1 \%$. A comparison of the concentrations of the four elements determined by using the present method can be carried out to differentiate among the 21 possible pairs that can be formed from 7 wires produced by different manufacturers.

Key words: ICP-MS, Analysis of trace elements, Steel wire, Forensic discrimination

\section{Introduction}

In criminal investigations of burglary and/ or homicide cases, steel wire that is used to bind a victim can serve as valuable physical evidence, because it can be compared with a similar type of wire found in the suspect's possession in order to connect a suspect with the crime ${ }^{1)}$. When two wires cannot be distinguished from each other by a scientific examination protocol for metal identification, it can be concluded that the two wires have originated from a common source and that the suspect has committed the crime. In the forensic comparison of inorganic materials with poor morphological characteristics, like a 
steel wire, the analysis and comparison of elemental compositions, particularly trace elements, is expected to be a useful method for achieving high discrimination power. In fact, a number of successful applications for similar types of metallic products, such as $\mathrm{Cu}$ wires ${ }^{2)}, \mathrm{Al}$ and $\mathrm{Au}$ foils ${ }^{3,4)}$, lead shotgun pellets ${ }^{5)}$ and solder6), have been reported.

In the examination of evidential materials, the analytical method employed must have high sensitivity and enable simultaneous multielement analysis, because it is necessary to analyze as many trace elements as possible within a short time using an extremely small and limited amount of physical evidence found at a crime scene. In addition, prior estimates of the evidential value achieved by the use of this method must be obtained on the basis of analytical results obtained for commercially available samples. If a pair of samples with different origins exhibit a remarkable difference in the elemental compositions in most cases, the analytical method can be used to achieve a high evidential value. In contrast, if different samples frequently show similar elemental patterns, the analytical method has poor discrimination power and cannot be used in an actual investigation.

Analytical techniques that have been investigated for iron base alloys involve radiochemical neutron activation analysis ${ }^{7)}$, glow discharge optical emission spectrometry ${ }^{8}$, flow-injection analysis ${ }^{9)}$, high-performance liquid chromatography ${ }^{10)}$, inductively coupled plasma atomic emission spectrometry and inductively coupled plasma mass spectrometry (ICP-MS) ${ }^{11,12)}$. However, these methods cannot be directly employed in cases involving physical evidence, because most of them have been developed for the quality control of industrial products, and thus, they require a large amount of the sample, which is not permissible in forensic science. Their applications in the analysis of physical evidence are also limited by the lack of analytical results for commercially available products collected from different sources; such results are essential for proving the evidential value of the method.

In the present study, the application of ICP -MS in the determination of minor and trace elements in steel wires after the removal of matrix iron by extraction into methyl isobutyl ketone (MIBK) was investigated. The evidential value of the proposed method was estimated on the basis of the analytical results obtained for wire samples produced by seven different manufacturers.

\section{Materials and Methods}

\section{Chemicals and Samples}

Purified water used throughout the present experiment was prepared using a Milli-Q SP system (Nihon Millipore, Tokyo, Japan). HCl, $\mathrm{HNO}_{3}$ and $\mathrm{H}_{2} \mathrm{SO}_{4}$ of ultrapure grade manufactured by Kanto Chemical (Tokyo, Japan) were used for the preparation of the standard solution and the dissolution of samples. MIBK (Kanto Chemical; Tokyo, Japan) for atomic absorption spectrometry was used for the extraction of the matrix iron in the sample solution. Multi-element standard solutions for the calibration of $\mathrm{Cr}, \mathrm{Mn}, \mathrm{Ni}$, and $\mathrm{Cu}$ and internal standard solution of $\mathrm{Y}$ were prepared by mixing and diluting single-element standard solutions $(1000 \mu \mathrm{g} / \mathrm{ml})$ for atomic absorption spectrometry, which were purchased from Kanto Chemical.

Standard Reference Material 16f (Basic Open-Hearth Steel, 1\% C) purchased from NIST was analyzed to confirm the accuracy and precision of the elemental concentrations determined by using the present method. Steel wires produced by seven different manufacturers were collected and analyzed, and the discrimination power achieved by comparing elemental compositions was estimated.

\section{Instruments}

The ICP-MS instrument employed was an Agilent model 7500c (Agilent Technologies, Tokyo, Japan). The operating conditions for the ICP-MS instrument are given in Table 1 .

\section{Procedure}

Five chips (approximately $10 \mathrm{mg}$ ) were cut from every $5 \mathrm{~mm}$ segment of a steel wire using a 
Table 1 Operating conditions for ICP-MS.

\begin{tabular}{ll}
\hline ICP-MS: Agilent $7500 \mathrm{c}$ & \\
Plasma condiiton & \\
RF power & $1.6 \mathrm{~kW}$ \\
Plasma gas flow rate & $15 \mathrm{l} / \mathrm{min}, \mathrm{Ar}$ \\
Auxilary gas flow rate & $0.9 \mathrm{l} / \mathrm{min}, \mathrm{Ar}$ \\
Carrier gas flow rate & $1.1 \mathrm{l} / \mathrm{min}, \mathrm{Ar}$ \\
Nebulizer & Babinton type \\
Data acquisition & \\
Elements $(m / z)$ & $\mathrm{Cr}(52), \mathrm{Mn}(55), \mathrm{Ni}$ \\
& $(60), \mathrm{Cr}(63)$ \\
Data point & $3 \mathrm{points} / \mathrm{peak}$ \\
Dwell time & $0.33 \mathrm{~s}$ \\
Integration & $1.0 \mathrm{~s}$ \\
Repetition & 3 times \\
\end{tabular}

machine saw. These chips were cut into smaller ones (approximately $5 \mathrm{mg}$ ) using a ceramic knife, washed by ultrasonication in acetone and in purified water for $5 \mathrm{~min}$, and dried in the oven. Each chip was accurately weighed, transferred into a plastic tube, and dissolved in a mixture of $100 \mu \mathrm{l} \mathrm{HCl}$ and $100 \mu \mathrm{l} \mathrm{HNO}_{3}$ by heating at $80^{\circ} \mathrm{C}$ in a water bath for $30 \mathrm{~min}$. After cooling to room temperature, $100 \mu \mathrm{l}$ of $5 \mu \mathrm{g} / \mathrm{ml}$ $\mathrm{Y}$ as the internal standard and $200 \mu \mathrm{l} \mathrm{HCl}$ were added to the solution prepared as mentioned above; this was followed by the removal of matrix iron by extraction into $200 \mu \mathrm{l}$ MIBK, which was repeated twice. Subsequently, $300 \mu \mathrm{l}$ of the aqueous phase in a teflon beaker was heated at $150^{\circ} \mathrm{C}$ for $1 \mathrm{~h}$ on a hot plate after the addition of $250 \mu \mathrm{l} \mathrm{H}_{2} \mathrm{SO}_{4}$. This solution was diluted to $25 \mathrm{ml}$ by $1 \% \mathrm{HNO}_{3}$ in a volumetric flask of polymethylpentene, and then the solution was used to determine the $\mathrm{Cr}, \mathrm{Mn}, \mathrm{Ni}$ and $\mathrm{Cu}$ concentrations by ICP-MS.

\section{Results and Discussion \\ 1. Analytical results for standard sample}

The concentrations of four elements $(\mathrm{Cr}$, $\mathrm{Mn}, \mathrm{Ni}$ and $\mathrm{Cu}$ ) in NIST $16 \mathrm{f}$ were determined in order to estimate the accuracy and precision of analytical results obtained by using the present method. Table 2 shows the measured mean values and the standard deviations obtained through five independent repetitions of sample
Table 2 Analytical Results for NIST stanfdard reference material $16 \mathrm{f}$.

\begin{tabular}{|c|c|c|c|}
\hline \multirow[b]{2}{*}{ Element } & \multicolumn{2}{|l|}{ Found } & \multirow{2}{*}{$\begin{array}{c}\text { Certified value } \\
\text { concentration } \\
(\mathrm{wt} \%)\end{array}$} \\
\hline & $\begin{array}{c}\text { concentration } \\
(w \mathrm{t} \%)^{\mathrm{a})}\end{array}$ & $\begin{array}{l}\text { RSD } \\
(\%)\end{array}$ & \\
\hline $\mathrm{Cr}$ & $0.019 \pm 0.004$ & 1.8 & $0.020 \pm 0.002$ \\
\hline Mn & $0.408 \pm 0.006$ & 1.5 & $0.404 \pm 0.006$ \\
\hline $\mathrm{Ni}$ & $0.008 \pm 0.0001$ & 1.0 & $0.008 \pm 0.002$ \\
\hline $\mathrm{Cu}$ & $0.005 \pm 0.0001$ & 2.1 & $0.006 \pm 0.001$ \\
\hline
\end{tabular}

a) Mean \pm SD for five measurements

preparation and measurement by ICP-MS. The elements listed in Table 2 were selected for the determination of concentrations because the semi-quantitative analysis of seven steel wires indicated significant differences in the concentrations of these elements among the wires produced by different manufacturers.

As seen from Table 2, the agreement between the measured values and the certified ones demonstrates that the concentrations of the four elements in steel can be determined with satisfactory good accuracy by using the present method. It is also expected that relative standard deviations (RSDs) lower than $2.1 \%$ can be used to compare the measured values for these elements and will offer the advantage of excellent discrimination power, if the variation in the elemental compositions among different wires is much greater than that within a single product.

\section{Analysis and discrimination of steel wires}

The present method was applied in the determination of the concentrations of $\mathrm{Cr}, \mathrm{Mn}$, $\mathrm{Ni}$ and $\mathrm{Cu}$ in seven different steel wires. The results are shown in Figs. 1(a) and (b). The length of the error bar in the graph corresponds to the range mean $\pm 2 \times \mathrm{SD}$, which is calculated on the basis of five independent repetitions of sample preparation and measurement by ICPMS.

The measured values for each of the four elements exhibited a small variation within a same wire. For instance, the maximum RSDs for a given sample were $1.7 \%$ for $\mathrm{Cr}$ in sample 3, 2.0 $\%$ for $\mathrm{Mn}, 1.7 \%$ for $\mathrm{Ni}$ and $5.4 \%$ for $\mathrm{Cu}$ in sample 6 . In contrast, a significant difference was 

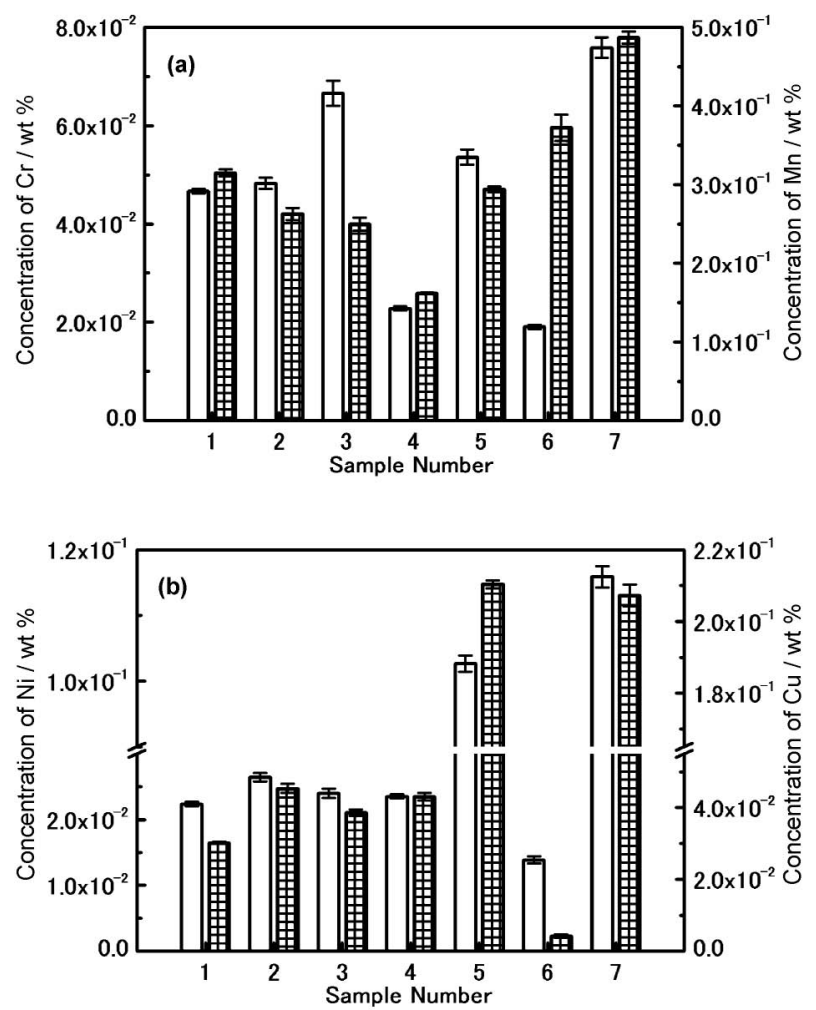

Fig. 1 Analytical results obtained by ICP-MS for different wire samples

(a) $\mathrm{Cr}(\square)$ and $\mathrm{Mn}($ 聿)

(b) $\mathrm{Ni}(\square)$ and $\mathrm{Cu}($ 进)

The length of the vertical line in the graph corresponds to the range Mean $\pm 2 \times \mathrm{SD}$.

observed in the values for different wires. In fact, the ratio of the maximum to minimum concentration for each element ranges from 3.0 for $\mathrm{Mn}$ to 50 for $\mathrm{Cu}$. These results demonstrate that the comparison of the concentrations for these elements is quite useful for the discrimination of different wires.

Steel wires were differentiated on the basis of analytical results in the following manner. The ranges (mean $\pm 2 \times \mathrm{SD}$ ) corresponding to each element were compared for two different samples. If the ranges overlapped for all the elements, the samples were considered to be indistinguishable, while if the ranges for one or more elements were non-overlapping, the samples were considered to be distinguishable. The number of possible pairs among the 7 different wires is calculated to be 21 by the equation ${ }_{7} \mathrm{C}_{2}(=(7 \times 6) /(2 \times 1))$. All of these 21 pairs could be differentiated by using this method.

\section{References}

1) Ohsaki, H., Kasamatsu, M., Suzuki, Y. and Suzuki, S.: Forensic discrimination of steel wire by determination of trace elements with ICP-AES. Bunseki Kagaku, 56, 11911195 (2007).

2) Marumo, Y: The discrimination of copper wires by flameless atomic absorption spectrophotometry. Report of the National Research Institute of Police Science (Research on Forensic Science), 33, 94-100 (1978).

3 ) Marumo, Y: Discrimination by comparison of trace elements contents 2 . Discrimination of aluminum articles by $\mathrm{X}$ ray fluorescence spectroscopy. Report of the National Research Institute of Police Science (Research on Forensic Science), 36, 205-210 (1983).

4) Kasamatsu, M., Suzuki, Y., Nakanishi, T., Shimoda O., Nishiwaki Y., Miyamoto N. and Suzuki, S.: Nondestructive analysis of silver in gold foil using synchrotron radiation X-ray fluorescence spectrometry. Anal. Sci., 21, 785-787 (2005).

5 ) Suzuki, Y. and Marumo, Y.: Determination of trace impurities in lead shotgun pellets by ICP-MS. Anal. Sci., 12, 129-132 (1996).

6) Suzuki, Y., Kasamatsu, M., Suzuki, S. and Marumo Y.: Forensic discrimination of lead-tin solder based on the trace impurity analysis by ICP-AES. Anal. Sci., 19, 415418 (2003).

7) Yamaguchi, N., Okada, Y., Suzuki, S., Hirai, S. and Mitsugashira, S.: Simultaneous determination of trace nickel and cobalt in high-purity iron by radiochemical neutron activation analysis. Bunseki Kagaku, 49, 683 -689 (2000).

8) Wagatsuma, K.: Precise determination of minor alloyed elements by glow discharge optical emission spectrometry with pulsed 
voltage modulation technique. Bunseki Kagaku, 53, 35-39 (2004).

9) Watanabe K., Osawa, T., Iwata, J and Itagaki, M.: Spectrophotometeric determination of arsenic in steels by FIA using filter-tube concentration method. Bunseki Kagaku, 55, 251-257 (2006).

10) Muramoto, T., Shigihara, S., Shimizu, T. and Uehara, N.: Fluorometric determination of trace amounts of selenium in steel by highperformance liquid chromatography with 2, 3-diaminonaphthalene. Bunseki Kagaku, 54, 959-963 (2005).
11) Sakamoto, S., Takada, K., and Wagatsuma, K.: Determination of trace amounts of elements in high-purity iron steels and $\mathrm{Cr}-\mathrm{Fe}$ alloy by ICP-OES after anion-exchange separation. Bunseki Kagaku, 54, 1039-1045 (2005).

12) Inose, M., Fujimoto, K., Kinoshiro, S. and Atsushi Chino: Depth profile analysis of precipitates and inclusions existing in the surface of the steel by inductively coupled plasma mass spectrometry with microwave decomposition. Bunseki Kagaku, 56, 93-98 (2007). 